\title{
Respeito em todo o tempo: um projeto transdisciplinar desenvolvido com estudantes dos quartos anos de uma escola de tempo integral
}

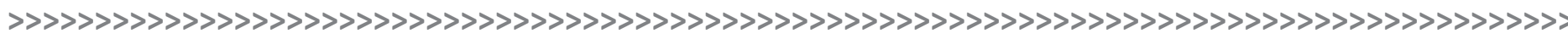

Hermínia Maria Martins Lima Silveira*

Roselene Alves Amâncio**

\begin{abstract}
Resumo:
Este trabalho versa sobre a trajetória de um projeto transdisciplinar intitulado "Respeito em todo o tempo", desenvolvido nas turmas iniciais do Segundo Ciclo de Formação Humana de uma escola de tempo integral. Busca-se aqui relatar e descrever algumas das atividades do projeto e apresentar reflexões sobre as possíveis implicações desse tipo de trabalho para a vida dos estudantes envolvidos. O objetivo do projeto foi convidar as crianças a refletirem sobre o respeito como essencial para fortalecer o convívio e a cooperação no espaço escolar, na tentativa de que eles possam se responsabilizar pelos seus atos, entendendo que, embora indivíduos, são parte importante da sociedade.
\end{abstract}

\section{Palavras-chave:}

Respeito. Ética. Formação humana.

\begin{abstract}
:
This work is about the trajectory of a transdisciplinary project entitled "Respect in all the time", developed in the initial classes of the Second Cycle of Human Formation of a full-time school. It is intended to report and describe some of the activities of the project and to reflect on the possible implications of this type of work for the lives of the students involved. The purpose of the project was to invite children to reflect on respect as essential to strengthening the coexistence and cooperation in school space, in an attempt to make them responsible for their actions, understanding that, although individuals, they are an important part of society.
\end{abstract}

\section{Keywords:}

Respect. Ethics. Human formation.

\section{Introdução}

Este trabalho apresenta um relato de experiência de um projeto transdisciplinar elaborado e desenvolvido por um grupo de professores nas turmas iniciais do Segundo Ciclo de Formação Humana de uma escola de tempo integral. A nossa proposta é compartilhar um pouco dos nossos desafios vivenciados nessas turmas e o processo de elaboração e desenvolvimento de ações desse projeto.

Para pensarmos as novas dinâmicas de organização escolar, é primordial refletirmos sobre as profundas transformações vivenciadas por outras instituições sociais, na tentativa

\footnotetext{
* Professora de Língua Portuguesa do Centro Pedagógico da Universidade Federal de Minas Gerais. E-mail: hemartinslima@yahoo.com.br.

** > Professora de Matemática do Centro Pedagógico da Universidade Federal de Minas Gerais. E-mail: roseleneamancio@ yahoo.com.br.
} 
de compreender a forma pela qual a sociedade se organiza em diferentes contextos social e histórico e os efeitos dessas transformações nas relações humanas.

A escola não pode se privar de dialogar sobre essas transformações, tendo em vista o seu papel enquanto instância de formação humana. $\mathrm{O}$ advento da globalização, as novas tecnologias digitais alteraram os tipos de relações interpessoais e estão produzindo significativas mudanças na construção subjetiva dos sujeitos. Estamos vivenciando novas formas de organização social e, portanto, novas formas de fazer laço social.

Dito isso, alguns questionamentos se fizeram e fazem presentes no nosso dia a dia: como a escola lida com essas transformações? de que modo a escola pode contribuir para o processo de formação humana, considerando as novas relações sociais? Não se tem a pretensão de tentar responder a essas questões, mas de apresentar como frutos desses questionamentos a elaboração e o desenvolvimento de um projeto coletivo transdisciplinar que foi capaz de proporcionar momentos de reflexão sobre as diferenças, a diversidade cultural, sobre ética, respeito e o exercício da alteridade.

A escola na atualidade torna-se, cada vez mais, o espaço em que as diferenças interpessoais ganham espaço e entram em conflitos. Ainda mais quando se trata de uma escola pública de tempo integral, na qual os alunos convivem em média sete horas diárias em um mesmo espaço tal como o é o Centro Pedagógico da UFMG. Neste panorama, um dos papéis fundamentais da escola é, sem dúvida, o de promover o respeito mútuo e a valorização das diferenças de forma a favorecer uma convivência respeitosa e cooperativa entre os sujeitos que coabitam o espaço escolar.

Neste sentido, a escola deve ser vista, sentida e praticada como o lugar em que o aprendizado das regras sociais e das normas de convivência precisa estar vinculado ao respeito ao outro, isto é, a coexistência, em igualdade dos diferentes. Para tanto, toda a comunidade escolar deve ser engajada a cultivar e a alimentar a cultura de ética, de respeito. Segundo os PCNs (BRASIL, 1998, p. 122), "reconhecer e valorizar a diversidade cultural é atuar sobre um dos mecanismos de discriminação e exclusão, entraves à plenitude da cidadania para todos".

Por isso, em uma escola que se quer democrática, isto é, em que deseja estimular a socialização de suas crianças através do convívio respeitoso e amigo, os conflitos devem ser debatidos, os preconceitos combatidos, as opiniões ouvidas e refletidas. Para isso, são necessárias estratégias de atuação e intervenção por parte do grupo de professores para serem implementadas com o apoio e a cooperação do grupo de alunos, de maneira a propiciar reflexões individuais e coletivas sobre a necessidade e a importância de respeitarmos e valorizarmos as diferenças e as semelhanças interpessoais.

\section{Questões do dia a dia da escola}

No início do ano escolar, observamos muitos conflitos relacionais nas duas turmas de natureza muito heterogênea. Alguns meninos apresentavam um discurso machista em relação às meninas, outros criticavam os colegas que usavam óculos, muitas meninas sentiam-se fragilizadas por causa do cabelo ou da cor da pele, alguns colegas eram excluídos das brincadeiras porque não se enquadravam no perfil estabelecido por um determinado grupo. Em uma das turmas havia um aluno de inclusão escolar cujas necessidades e atendimentos específicos eram questionados pelos colegas de sala, uma vez que eles não sabiam do laudo médico do colega e isso, de certa forma, contribuía para a construção de um enigma para as crianças e, também, de um certo mal-estar entre elas. Muitas delas apresentavam um comportamento agressivo em relação às atitudes desse estudante de necessidades especiais, ficavam enciumadas em relação ao modo como ele era tratado pelos professores e monitores da turma. Havia momentos em que a autoridade 
dos monitores ela colocada em xeque, muitos questionamentos eram feitos em relação à hierarquia, havia sempre uma postura muito ríspida da maioria da turma em relação às diferenças, quaisquer que fossem elas.

Diante desse cenário que estava se desenhando, de conflitos e de intolerância, inclusive de agressões físicas e verbais entre os colegas, os professores dos quartos anos avaliaram que seria necessário elaborar e desenvolver algumas atividades de intervenção que fossem capazes de promover momentos de debates, de reflexão, de diálogo (roda de conversa) com os estudantes sobre as questões do dia a dia ${ }^{1}$.

A intenção do grupo era que esse conjunto de atividades trabalhasse a necessidade e a importância de se respeitar as pessoas sempre, de uma forma que os alunos se sentissem realmente implicados e responsabilizados pelas suas atitudes nas situações de conflito, na tentativa de sensibilizá-los para a compreensão da importância do respeito mútuo, evitando situações de bullying e de preconceito e intervindo nos conflitos através do diálogo e da cooperação.

De acordo com os PCNs (BRASIL, 1998, p. 139), os professores precisam estimular em seus alunos "a sensibilidade em relação ao outro", fazendo-os "compreender que aquele que é alvo de discriminação sofre de fato, e de maneira profunda". Então, é essencial "que o professor, em sala de aula, possa escutar até o que não foi dito" e, em muitos casos, “como a história do preconceito é muito antiga, muitos dos grupos vítimas de discriminação desenvolveram um medo profundo e uma cautela permanente como reação", por isso, "o professor precisa saber que a dor do grito silenciado é mais forte que a dor pronunciada" (BRASIL, 1998, p. 139).

Nesse sentido, Imbernón (2001, p. 39) destaca que "o eixo fundamental do professor é o desenvolvimento da capacidade de refletir sobre a própria prática docente, com o objetivo de aprender a interpretar, compreender e refletir sobre a realidade social e a docência”.

\section{Metodologia de trabalho}

Este trabalho é de caráter qualitativo, de natureza empírica. Logo, o relato foi construído a partir das anotações em um diário de observação durante o desenvolvimento do projeto e das observações diárias dos novos modos dos estudantes se relacionarem com os colegas, consigo mesmos e com os conflitos que se apresentavam.

Lançamos mão da noção de atividade desenvolvida por Leontiev (2006, p. 68-69) para discorremos sobre a concepção de atividade que fundamenta este trabalho. Para esse teórico, toda atividade humana é um processo em que o homem realiza uma determinada tarefa instigada por um determinado motivo. O modo de realização de uma atividade se dá pelo modo como o homem se relaciona com o mundo, tendo como marca radical o contexto social e histórico no qual o sujeito encontra-se inserido.

Ressalta-se, então, que uma mesma atividade pode ser realizada de diferentes maneiras, tendo em vista a possibilidade que cada indivíduo tem para desenvolver formas de se relacionar em diferentes processos de interação. É na e pela relação que as significações são constituídas; “a significação é, portanto, a forma sob a qual um homem assimila a experiência humana generalizada e refletida” (LEONTIEV, 2004, p. 101). Importa dizer que uma única atividade pode envolver várias ações e não há necessariamente uma relação direta entre elas e entre o que as motivou.

A título de ilustração, na Figura 1 apresentamos um esquema com a estrutura hierárquica de uma das atividades do projeto destacando a organização entre seus constituintes.

$1>0$ processo de elaboração das atividades será apresentado com mais vigor na seção de Metodologia. 
Figura 1 - Esquema com a estrutura hierárquica de uma das atividades.

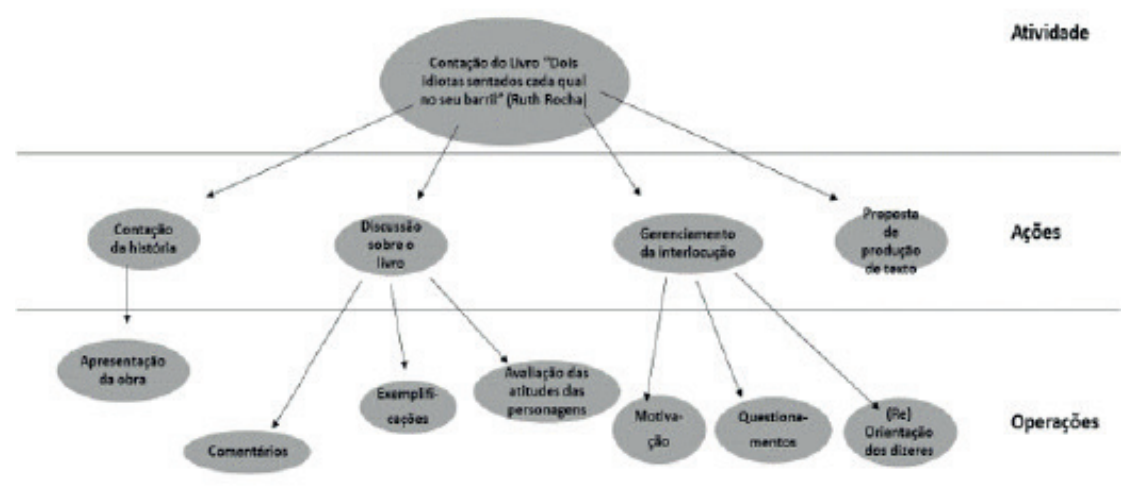

Fonte: Elaborado pelas autoras. ${ }^{2}$

Discorreremos de modo mais detalhado sobre essa atividade representada no esquema acima cujo objetivo era refletir sobre as relações com o outro, sobre as diferenças de opinião e de sentimento. O primeiro contato das crianças com o livro se deu por meio da apresentação da capa, leitura do título da obra e leitura de um pequeno texto presente na contra capa "Um é teimosinho. O outro é mandão. O que pode acontecer quando esses dois idiotas, sentados cada qual no seu barril de pólvora, com uma vela acesa na mão, se encontram para provar sua valentia?”.

Antes da contação, as crianças foram convidadas a produzirem hipóteses a respeito do desenrolar da história a partir dos elementos apresentados a elas: "O que sugere o título da obra? E as imagens da capa? Conhecem a história?”.

Os dois homens, protagonistas da história, embora correndo o mesmo risco, cada um, a seu modo, apresentava argumentos exigindo que a vela do outro fosse apagada e, por conseguinte, mantivesse a sua vela acessa. Eles desconsideravam o perigo da explosão do barril como sendo um risco vivenciado pelos dois e, assim, a verdade de cada personagem passa a ser a sua única verdade. A teimosia é o fio condutor da discussão entre as personagens e ao longo da conversa eles pedem aos filhos para trazerem mais artefatos de natureza explosiva na tentativa de "alimentar" o poder de combate: "E assim os dois idiotas, com suas velas na mão, foram ajuntando bombas, ajuntaram coleção! [...]”.

A briga, que parecia não ter fim, foi interrompida com a queda da vela do Teimoso que se assusta com o espirro do Mandão e a confusão termina com uma grande explosão: "lá se vão os idiotas: era uma vez um teimoso, era uma vez um mandão..."

A contação da história pela professora foi acompanhada da apresentação das imagens do livro projetadas para a turma. Nesse momento, as crianças fizeram intervenções em relação à cena que era apresentada e aos argumentos dos protagonistas.

Após esse momento, alguns questionamentos foram feitos para que pudessem guiar a discussão: Gostaram da história? Quais as impressões em relação às imagens? Qual(is) o(s) motivo(s) dos dois personagens brigarem tanto? O que vocês acham do(s)

$2>$ Esse esquema se pauta em "Rede de atividades e práticas de letramento: relações entre espaços individuais e coletivos; interfaces entre movimentos singulares e práticas sociais", trabalho apresentado por Silva e Matencio no I SIMELP - Simpósio Mundial de Estudos de Língua Portuguesa, São Paulo - 01 a 05 de setembro de 2008. motivo(s) das brigas? O conflito entre as personagens poderia ser evitado? Qual(is) era $(m)$ $o(s)$ sentimento(s) que predominava $(m)$ na relação entre as personagens? Já vivenciaram esse(s) sentimento(s). Contem como foi essa experiência. Vamos refletir sobre a palavra "idiota" presente no título do livro.

A última ação dessa atividade foi a proposta de produção por escrito de um outro final para a história do livro. Essa atividade foi realizada em dupla e, logo em seguida, socializada para a turma. Nesse momento, foram suscitadas questões sobre quais as razões 
para produção de determinado final para história e não outro. As crianças, então, comentaram sobre as possibilidades de escolha que as pessoas têm e a importância de assumi-las.

O projeto de ensino "Respeito em todo o tempo" foi composto por doze diferentes atividades, durante todo o ano letivo, cujas ações foram mediadas por instrumentos diversificados (livros, filmes, texto imagético, música, dentre outros) capazes de significar as atividades de acordo com a motivação inicial de cada uma. As atividades foram elaboradas e desenvolvidas pelos docentes dos diversos componentes curriculares e pelos monitores das turmas nos vários encontros coletivos. Elas foram elaboradas e rediscutidas durante todo o processo de desenvolvimento do projeto considerando sempre os retornos por parte dos alunos em relação às atividades anteriores e as novas questões que iam surgindo.

Esse modo de elaboração das atividades do projeto possibilitou que os estudantes, aqueles que realizam as ações da atividade proposta, reflitam sobre elas e proponham novas atividades e ações para atingir os objetivos pretendidos pelo grupo, num movimento de negociações, de trocas, sempre guiado pelo motivo da atividade em foco. Essa dinâmica proporciona o desenvolvimento de uma "pedagogia" do protagonismo.

A primeira ação desenvolvida no projeto foi a apresentação dele para as turmas, nesse momento a professora responsável pela realização dessa atividade fez uma roda de conversa com a turma a partir de algumas questões-guia como: O que é respeito? Quem devemos respeitar? Existem situações em que não é necessário respeito? É fácil ou difícil tratar as pessoas com respeito? Você já se sentiu desrespeitado? Como foi essa sensação?

O espaço de circulação da palavra proporcionou aos alunos um momento de reflexão sobre suas atitudes, permitiu que eles ouvissem os colegas, possibilitou que alguns dizeres que vieram à tona fossem questionados, num movimento de interrogação e reelaboração dos modos como cada um lida com o outro e com os conflitos.

Vale ressaltar que havia nos dizeres dos alunos um discurso "pronto" sobre a noção de respeito que não era condizente com o modo de agir deles. Buscou-se, então, direcionar a conversa no sentido de que eles falassem mais das suas experiências e vivências, na tentativa de desconstrução desses discursos cristalizados que fazem eco àquilo que é dar ordem da moral.

A dinâmica "o feitiço virou contra o feiticeiro" foi uma das atividades do projeto. O objetivo dessa atividade foi propiciar um processo de empatia e de projeção em relação ao outro. Para tanto, propiciou um espaço de reflexão sobre a necessidade de tratar o outro como nós gostaríamos de ser tratados, desenvolvendo, assim, a capacidade de ser altruísta. Nesse sentido, o outro precisa ser percebido na sua diferença, tendo em vista os seus saberes culturais, familiares e subjetivos, ou seja, que a verdade de um sujeito não necessariamente é a verdade do outro.

A primeira ação foi que cada um escrevesse em uma folha o que gostaria que a pessoa à sua direita realizasse sem que ninguém visse. Depois de todos terem realizado o registro, ele é socializado para a turma e o nome da atividade também é revelado - "O feitiço virou contra o feiticeiro". Nesse momento, é muito interessante observar e perceber como os estudantes ficam incomodados em relação aos seus próprios desejos e ao que eles precisavam fazer, uma vez que cada aluno teria que realizar aquilo que indicou para o colega. Alguns registros das falas dos alunos sobre esse momento foram realizados: "se eu soubesse que era para mim”, “ainda bem que eu indiquei uma coisa boa para fazer", "eu não quero realizar o que eu desejei".

O professor responsável pela realização da dinâmica fez algumas intervenções importantes ao retomar os próprios dizeres da turma para uma reflexão coletiva, destacando como é importante desenvolver a capacidade de se colocar, na medida do possível, no lugar do outro.

Uma outra atividade do projeto foi a elaboração de coreografia a partir da música "Black or White" (Michael Jackson), com intuito de refletir sobre as diferenças raciais e culturais. As crianças ouviram a música e assistiram ao clipe. Logo em seguida, em uma roda de conversa, foram trazidas questões sobre como as diferenças raciais e culturais 
estão presentes no contexto escolar (cor da pele, cabelo, gostos musicais, filiação religiosa, dentre outras). O processo de criação coletiva da coreografia se deu a partir dessa reflexão. A dança foi apresentada pelos alunos no evento "Mostra de Dança" da escola.

$\mathrm{Na}$ tentativa de envolver os familiares nas questões discutidas no projeto com as crianças, ao longo do ano letivo realizamos reuniões coletivas para apresentarmos e refletirmos sobre as ações e os resultados dessas ações.

\section{Conclusão}

Esperou-se que o desenvolvimento do projeto pudesse colaborar para que as crianças desenvolvessem atitudes mais respeitosas com professores, monitores, técnico e, principalmente, com seus colegas. Além disso, foi esperado também que alunos que sofrem desrespeito pudessem se sentir mais fortalecidos para aprender a se colocar diante das situações vivenciadas.

O respeito deve ser, portanto, objeto de prática social e não apenas elemento discursivo. Por isso, por meio da implantação das ações do projeto "Respeito em todo o tempo", os alunos foram estimulados a refletir sobre as situações em que sofrem ou praticam desrespeito, preconceito e bullying; reconhecer e valorizar a diversidade étnica e sociocultural e a pensar sobre formas de melhor se relacionar e conviver amigavelmente com as pessoas da escola (companheiros da sala e de outras salas, funcionários, monitores, professores, etc.). Buscou-se, ainda, que nossos alunos do Centro Pedagógico compreendessem a importância de se valorizar e de se respeitar o outro e que desenvolvam, efetivamente, o hábito do diálogo na resolução de seus conflitos.

Em se tratando de projeto que busca proporcionar o desenvolvimento da maturidade dos sujeitos nas relações interpessoais, contribuindo para a sua formação cidadã, admite-se que não é possível controlar os efeitos dessa ação sobre os estudantes, logo, há possibilidade de efeitos diversos, de possíveis elaborações subjetivas. O desenvolvimento do projeto parece ter colaborado para que os estudantes tivessem maior compreensão da importância da coletividade, desenvolvendo o sentimento de alteridade, acolhendo o outro na sua diferença e percebendo que a singularidade de cada sujeito é um aspecto positivo na experiência cotidiana escolar e de qualquer outro ambiente.

\section{Referências}

BRASIL. Secretaria de Educação Fundamental. Parâmetros curriculares nacionais: pluralidade cultural. Brasília, DF: MEC/SEF, 1998.

IMBERNÓN, Francisco. A profissão docente diante dos desafios da chamada sociedade globalizada, do conhecimento ou da informação. In: IMBERNÓN, Francisco. Formação docente e profissional: formar-se para a mudança e a incerteza. São Paulo: Cortez, 2001. p. 38-44

LEONTIEV, Alexis N. O desenvolvimento do psiquismo. 2. ed. São Paulo: Centauro, 2004.

LEONTIEV, Alexis N. Uma contribuição à teoria do desenvolvimento da psique infantil. In: VIGOTSKII, Lev Semenovitch; LURIA, Alexander Romanovich; LEONTIEV, Alexis N. Linguagem, desenvolvimento e aprendizagem. Tradução: Maria da Penha Villalobos. São Paulo: Ícone, 2006. p. 59-83. 